\title{
Removal of Lead from Water by Liquid-Liquid Extraction using trihexyltetradecylphosphonium Chloride in Different Diluents
}

\author{
Evon Ooi ${ }^{1}$ and Yee Sern $\mathrm{Ng}^{1 *}$ \\ ${ }^{1}$ Lee Kong Chian Faculty of Engineering and Science, Universiti Tunku Abdul Rahman, Jalan Sungai \\ Long, Bandar Sungai Long, Cheras, 43000 Kajang, Selangor, Malaysia
}

\begin{abstract}
The feasibility of ionic liquid trihexyltetradecylphosphonium chloride [THTDP][Cl] as extractant in different diluents for the removal of lead $(\mathrm{Pb})$ from water was investigated using laboratory scale liquid-liquid extraction. The tests were conducted using an extraction mixture which consisted of $5 \%(\mathrm{v} / \mathrm{v})[\mathrm{THTDP}][\mathrm{Cl}]$ in different diluents, namely toluene and corn oil. In general, the extraction followed anion exchange mechanism and equilibrium extraction can be achieved at extraction time of 5-10 minutes. In addition, the extraction efficiency was found to decrease when the $\mathrm{HCl}$ concentration in $\mathrm{Pb}$ solution was increased from $1 \mathrm{M}$ to $3 \mathrm{M}$ for both types of diluents, as a result of competition between excessive $\mathrm{Cl}^{-}$and $\mathrm{PbCl}_{4}^{2-}$ to form complex with [THTDP] cation. The extraction ability of $\mathrm{Pb}$ for [THTDP][Cl] was highly dependent on the types of diluents used where corn oil based extraction mixture showed lower extraction efficiency in comparison to toluene based extraction mixture, as a result of its higher viscosity.
\end{abstract}

\section{Introduction}

Liquid-liquid extraction is one of the popular water treatment technologies for the removal of heavy metals and organic compounds. The conventional extraction mixtures consist of organic based solvents and extractants, which normally have high vapour pressure, flammability and toxicity. These properties often rise up issues on the chemicals handling and additional cost due to solvent loss.

Vegetable oils and ionic liquids appear to be suitable candidates in replacing the organic solvents and extractants, respectively, in liquid-liquid extraction process. Vegetable oils are generally less toxic in comparison to organic solvents, which make them a favourable choice to be applied as the diluent in liquid-liquid extraction for improving the environmental friendliness of this process in water treatment. From the view of extractants, ionic liquids are a group of room temperature molten salts that consist of organic cations and organic/inorganic polyatomic anions. Due to their salt characteristics, they generally have negligible volatility, less flammable and they are tunable based on the requirement of the

* Corresponding author: ngys@utar.edu.my 
process [1-3], and these properties generally show their favorability to replace the organic based extractants/solvents.

In the past decade, ionic liquids with imidazolium cations have been investigated extensively and have proven to show superior performance in extracting organic compounds and heavy metals from aqueous solutions using liquid-liquid extraction [4-9]. However, it is worth noting that imidazolium based ionic liquids, especially with hydrophobic characteristic are normally costly. Therefore, their feasibility in large scale application remains a concern. In contrast, ammonium and phosphonium based ionic liquids are recently being investigated as a new type of ionic liquids in liquid-liquid extraction process due to the fact that they are more stable than imidazolium based ionic liquids [10]. These ionic liquids have been reported to show favorable performance in extraction of cellulose [11], dyes [12] and heavy metals [6, 13-14]. Nevertheless, investigations on the role of phosphonium based ionic liquids in liquidliquid extraction mechanisms of heavy metals from water are still limited.

The present study investigated the application of ionic liquid trihexyltetradeculphosphonium chloride [THTDP][Cl], as the extractant in different diluents, namely toluene and corn oil for the removal of lead $(\mathrm{Pb})$ from acidic solution using liquidliquid extraction. The effect of different operating parameters such as extraction time, initial $\mathrm{Pb}$ concentration and $\mathrm{HCl}$ concentration on the extraction efficiency was investigated in this study. Lastly, a comparison on the extraction efficiency between the corn oil based extraction mixture and toluene based extraction mixture was also carried out.

\section{Methodology}

\subsection{Materials}

The ionic liquid extractant, trihexyltetradecylphosphonium chloride [THTDP][Cl] was purchased from Sigma Aldrich. The extraction solvents/diluents used in this study were corn oil and toluene. Lead nitrate, $\mathrm{Pb}\left(\mathrm{NO}_{3}\right)_{2}$ was used as the heavy metal candidate in this study and it was supplied by R\&M Chemicals.

\subsection{Experimental procedure}

The extractant, [THTDP][Cl] was mixed with the diluent (corn oil or toluene) using magnetic stirrer to produce $5 \%(\mathrm{v} / \mathrm{v})$ extractant mixture. A solution of $100 \mathrm{ppm}$ of $\mathrm{Pb}$ was prepared by dissolving the pre-calculated amount of $\mathrm{Pb}\left(\mathrm{NO}_{3}\right)_{2}$ into $3 \mathrm{M} \mathrm{HCl}$ solution. The extraction test was conducted by contacting $5 \mathrm{~mL}$ of the extraction mixture with $8 \mathrm{~mL}$ of $\mathrm{Pb}$ solutions in a glass vial and the mixture was homogenized for 15 minutes using a magnetic stirrer. After the extraction process, $1 \mathrm{~mL}$ of sample was taken from the aqueous phase and it was diluted with $9 \mathrm{~mL}$ of distilled water. The $\mathrm{Pb}$ concentration in the diluted sample was analyzed using ICP-OES. The extraction efficiency can be determined using Equation (1), where $\mathrm{C}_{\mathrm{i}}$ is the initial $\mathrm{Pb}$ concentration and $\mathrm{C}_{\mathrm{f}}$ is the final $\mathrm{Pb}$ concentration after the extraction process.

$$
\text { Extraction efficiency, } \%=\frac{C_{i}-C_{f}}{C_{i}} \times 100
$$




\section{Results and discussion}

The study was investigated for three parameters, namely i) extraction time, ii) initial $\mathrm{Pb}$ concentration, iii) $\mathrm{HCl}$ concentration in the $\mathrm{Pb}$ solution, and iv) types of diluents. The results are further discussed in their respective sub-section.

\subsection{Effect of extraction time}

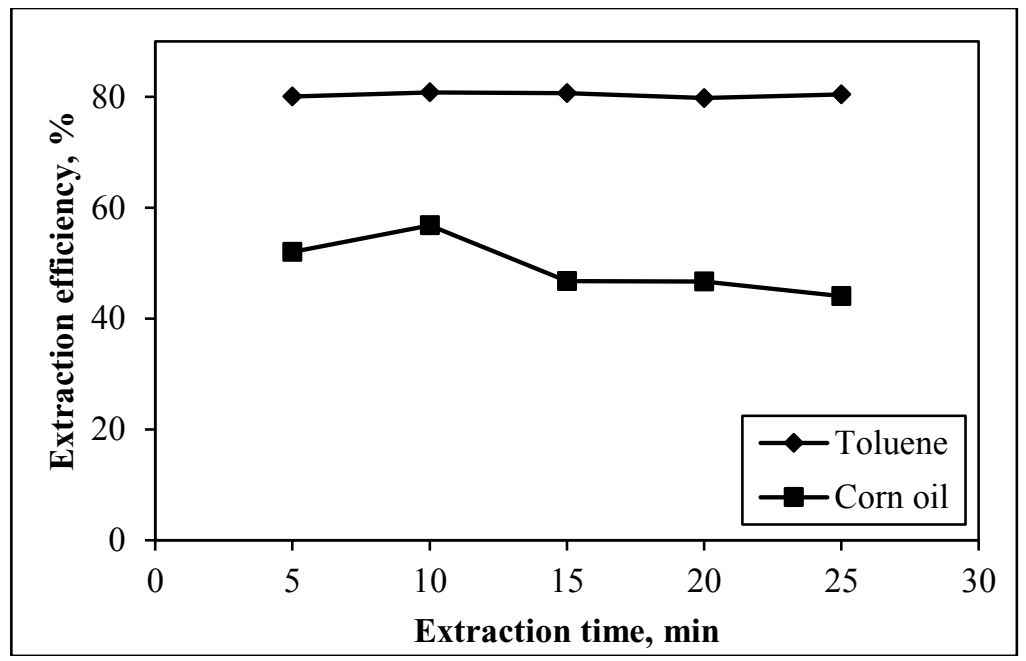

Fig. 1. Effect of extraction time on the extraction efficiency of $\mathrm{Pb}$ using $5 \%(\mathrm{v} / \mathrm{v})$ trihexyltetradecylphosphonium chloride in different diluents (Initial $\mathrm{Pb}$ concentration: $100 \mathrm{ppm} ; \mathrm{HCl}$ concentration: $3 \mathrm{M}$ )

The effect of extraction time was investigated from 5 minutes to 25 minutes. In general, it is found that equilibrium extraction can be achieved at short extraction time i.e. 5-10 minutes for both types of diluents, as shown in Fig. 1. An extraction efficiency of $80 \%$ can be achieved in 5 minutes when toluene was applied as the diluents and the efficiency was maintained at prolonged extraction time, indicated that the extraction equilibrium had been achieved. However, a different trend was observed when corn oil was applied as the diluent in the extraction mixture. Fig. 1 shows that equilibrium extraction is achieved within 5-10 minutes, but at a lower lower extraction efficiency range of $44-56 \%$. Further increase in the extraction time from 10 minutes to 25 minutes was found not to improve the extraction. Instead, a slight reduction in the extraction efficiency was observed.

\subsection{Effect of initial $\mathrm{Pb}$ concentration}

Fig. 2 illustrates the effect of initial $\mathrm{Pb}$ concentration on the extraction efficiency. In general, the results showed that the extraction efficiency was slightly increased at higher initial $\mathrm{Pb}$ concentration for both types of diluents. The variation in the extraction efficiency for toluene and corn oil based extraction mixture is in a small range of $78-86 \%$ and $51-59 \%$, respectively, even though the initial $\mathrm{Pb}$ concentration is increased from $50 \mathrm{ppm}$ to $150 \mathrm{ppm}$, as shown in Fig. 2. Theoretically, the use of $5 \%(\mathrm{v} / \mathrm{v})[\mathrm{THTDP}][\mathrm{Cl}]$ was adequate in removing all the $\mathrm{Pb}$ from the aqueous solutions for both low and high initial $\mathrm{Pb}$ concentration. However, the experiment results showed that $100 \%$ extraction efficiency was not achievable. Instead, a stable extraction efficiency was obtained for both toluene and corn oil based extraction mixtures, regardless of initial $\mathrm{Pb}$ concentration. This could be mainly caused by the nature of 
the extraction process in this study. The extraction mechanism is believed to be the anionic exchange for the formation of hydrophobic [THTDP]- $\mathrm{PbCl}_{4}$ complex that is soluble in the extraction mixture, as shown in Equation (2). The results suggested that the reaction for the complex formation is reversible and equilibrium extraction will be achieved. Nevertheless, it is worth noting that the uptake of $\mathrm{Pb}$ from the aqueous solution at higher initial $\mathrm{Pb}$ concentration is increased substantially, as shown in Fig. 2, suggesting that the saturation uptake of $\mathrm{Pb}$ by the extraction mixture is not being achieved yet.

$$
\mathrm{PbCl}_{4}^{2-}+2[\mathrm{THTDP}][\mathrm{Cl}] \Leftrightarrow[\mathrm{THTDP}]_{2}\left[\mathrm{PbCl}_{4}^{2-}\right]+2 \mathrm{Cl}^{-}
$$

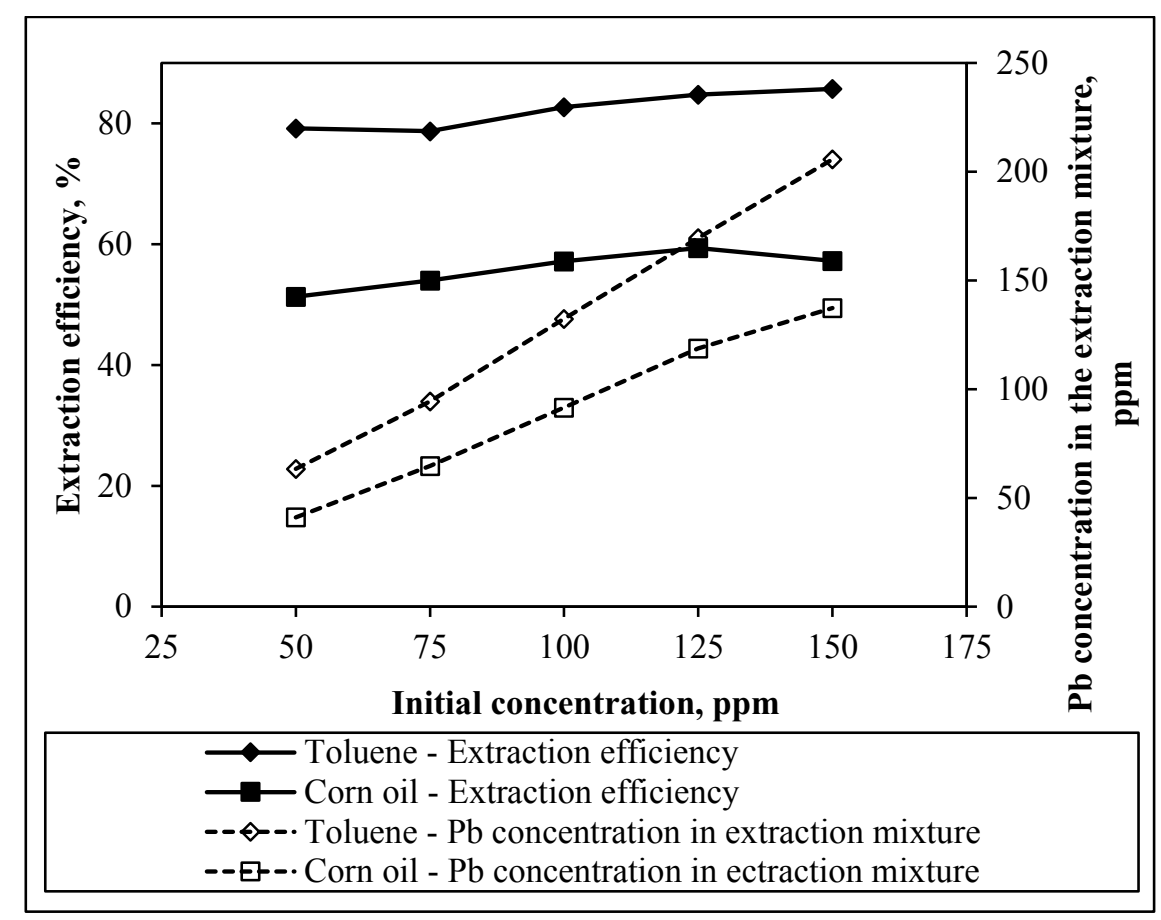

Fig. 2. Effect of initial $\mathrm{Pb}$ concentration on the extraction efficiency and $\mathrm{Pb}$ concentration in the extraction mixture using $5 \%(\mathrm{v} / \mathrm{v})$ trihexyltetradecylphosphonium chloride in different diluents (Extraction time: 15 minutes; $\mathrm{HCl}$ concentration: $3 \mathrm{M}$ )

\subsection{Effect of $\mathrm{HCl}$ concentration}

The effect of $\mathrm{HCl}$ concentration in $\mathrm{Pb}$ solution was investigated from $1 \mathrm{M}$ to $3 \mathrm{M}$. The use of $\mathrm{HCl}$ is essential for two purposes: i) to provide low $\mathrm{pH}$ condition to ensure that $\mathrm{Pb}$ is in ionic form, and ii) to provide $\mathrm{Cl}^{-}$ion for the formation of $\mathrm{PbCl}_{4}{ }^{2-}$. The formation of $\mathrm{PbCl}_{4}{ }^{2-}$ is important to ensure that anionic exchange mechanism as shown in Equation (2) can occur in the $\mathrm{Pb}$ extraction process. 


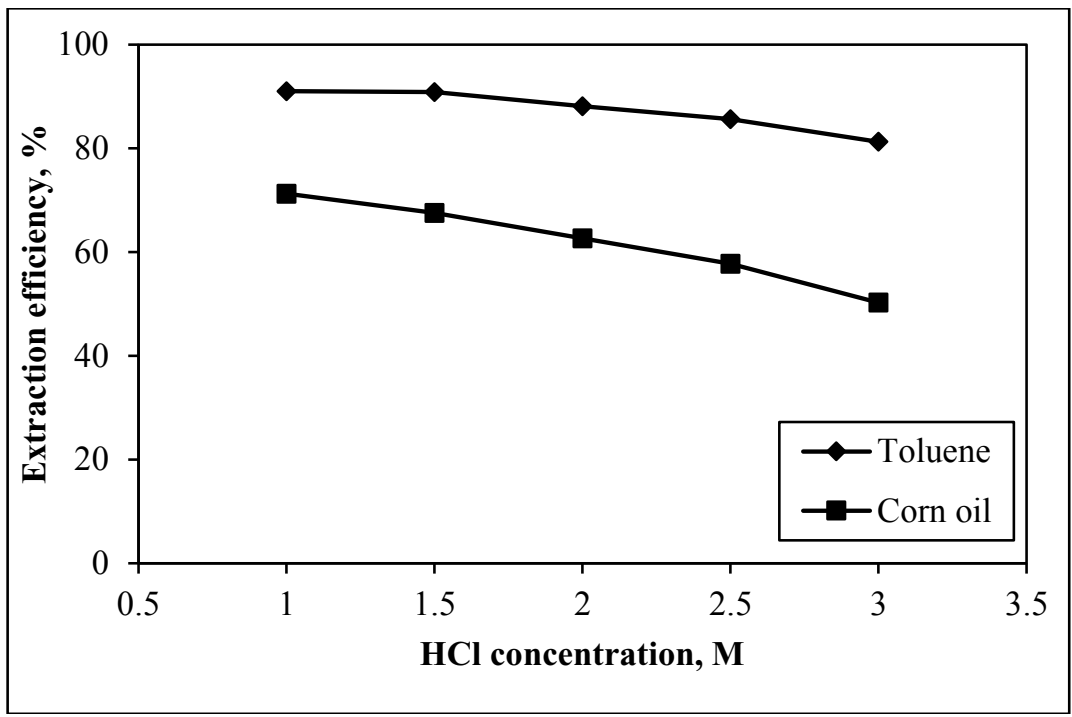

Fig. 3. Effect of $\mathrm{HCl}$ concentration on the extraction efficiency of $\mathrm{Pb}$ using $5 \%(\mathrm{v} / \mathrm{v})$ trihexyltetradecylphosphonium chloride in different diluents (Extraction time: 15 minutes; Initial $\mathrm{Pb}$ concentration: $100 \mathrm{ppm}$ )

In general, it is claimed that a low $\mathrm{pH}$ and high $\mathrm{HCl}$ concentration are required in order to ensure the metal species is in $\mathrm{MeCl}_{4}{ }^{2-}$ form. This has been discussed by Mirea et al. [15] whereby higher $\mathrm{HCl}$ concentration provides better anion exchange. However, a reverse trend is found in the present study, as shown in Fig. 3 whereby the increase of $\mathrm{HCl}$ concentration in $\mathrm{Pb}$ solution from $1 \mathrm{M}$ to $3 \mathrm{M}$ is found to decrease the extraction efficiency, regardless the types of diluents used. The results suggested that an excessively high $\mathrm{HCl}$ concentration was not required to ensure smooth anionic exchange extraction. This was in line with the work of Bhatluri et al. [16] and Regel-Rosocka et al. [13] in the extraction of cadmium and palladium. Bhatluri et al. [16] suggested that the excessive concentration of $\mathrm{HCl}$ in the metal solution led to lower extraction efficiency due to the competitive environment between $\mathrm{Cl}^{-}$and $\mathrm{MeCl}_{4}{ }^{2-}$ to form complex with [THTDP] cation. The results in this study were believed to be caused by this reason as the number of mole of $\mathrm{HCl}$ used was 2070-6210 times higher than $\mathrm{Pb}$. Excessive free $\mathrm{Cl}^{-}$ions in the solution may compete with $\mathrm{PbCl}_{4}{ }^{2-}$ in the complexation process. Thus, lower extraction efficiency was observed at high $\mathrm{HCl}$ concentration.

\subsection{Effect of types of diluents}

The feasibility of greener extraction mixture that comprises of [THTDP][Cl] and corn oil was evaluated by comparing with the conventional organic diluent, toluene. In general, it is found that the extraction efficiency under corn oil based extraction mixture is relatively lower than toluene based extraction mixture, as shown in Figs. 1, 2 and 3. This was plausibly to be caused by the viscosity of the diluent, as the viscosity of corn oil is relatively higher than toluene [17-18]. Therefore, the well mixed condition was poorer for corn oil based extraction mixture under similar stirring speed and this further caused slower mass transfer rate and the extraction efficiency. Nevertheless, it is suggested that the use of higher stirring speed and enhanced mixing condition may help in improving the performance of corn oil based extraction mixture. 


\section{Conclusions}

The ability of ionic liquid trihexyltetradecylphosphonium chloride [THTDP][Cl] as extractant in different diluents for the removal of $\mathrm{Pb}$ from water was evaluated. The results showed that the ionic liquid can extract $\mathrm{Pb}$ from $\mathrm{HCl}$ solution effectively via anionic exchange mechanism. The extraction was fast and equilibrium extraction can be achieved within 5-10 minutes. From the view of solution condition, it was found that highest extraction efficiency was achieved at $1 \mathrm{M} \mathrm{HCl}$ concentration and further increase in $\mathrm{HCl}$ concentration reduced the extraction efficiency, as a result of competition between $\mathrm{Cl}^{-}$and $\mathrm{PbCl}_{4}{ }^{2-}$ in complex formation with [THTDP] cation. The performance of ionic liquid as extractant was highly dependent on the types of diluent, where high viscosity diluents will impede the extraction process.

This work is financially supported by Universiti Tunku Abdul Rahman and UTARRF grant IPSR/RMC/UTARRF/2017-C1/N02.

\section{References}

1. S. Keskin, D. Kayrak-Talay, U. Akman, Ö. Hortaçsu, J. Supercrit. Fluid. 43, 150-180 (2007)

2. A. Berthod, M. J. Ruiz-Ángel, S. Carda-Broch, S. J. Chromatogr. A 1184, 6-18 (2008)

3. D. M. Fox, J. W. Gilman, A. B. Morgan, J. R. Shields, P. H. Maupin, R. E. Lyon, H. C. De Long, P. C. Trulove, Ind. Eng. Chem. Res. 47, 6327-6332 (2008)

4. J. Fan, Y. Fan, Y. Pei, K. Wu, J. Wang M. Fan, (2008). Sep. Purif. Technol. 61, 324$331(2008)$

5. U. Domańska, A. Rękawek, J. Solution Chem. 38, 739-751 (2009)

6. L. Fischer, T. Falta, G. Koellensperger, A. Stojanovic, D. Kogelnig, M. Galanski, R. Krachler, B. K. Keppler, S. Hann, Water Res. 45, 4601-4614 (2011)

7. M. A. Didi, B. Medjahed, W. Benaouda, Am. J. Analyt. Chem. 4, 40-47 (2013)

8. Q. Li, P.Angeli, Chem. Eng. Sci. 143, 276-286 (2016)

9. C. Shi, Y. Jing, Y. Jia, J. Mol. Liq. 215, 640-646 (2016)

10. K. Ghandi, Green Sustain. Chem. 4, 44-53 (2014)

11. A. J. Holding, A. Parviainen, I. Kilpelainen, A. Soto, A. W. T. King, H. Rodriguez, RSC Adv. 7, 17451-17461 (2017)

12. Z. Ullah, M. A. Bustam, Z. Man, A. S. Khan, ARPN J. Eng. Appl. Sci. 11, 1653-1659 (2016)

13. M. Regel-Rosocka, M. Rzelewska, M. Baczynska, M. Janus, M. Wisniewski, Physicochem. Probl. Mi. 51, 621-631 (2014)

14. W. Wei, C. -W. Cho, S. Kim, M. -H. Song, J. K. Bediako, Y. -S. Yun, J. Mol. Liq. 216, 18-24 (2016).

15. C. M. Mirea, I. Diaconu, E. Ruse, E. A. Serban, D. D. Clej, G. A. Popa, E. F. Popa, G. Nechifor, Prog. Cryog. Isotop. Separ. 19, 45-54 (2016)

16. K. K. Bhatluri, M. S. Manna, P. Saha, A. K. Ghoshal, J. Memb. Sci. 459, 256-263 (2014)

17. S. Sahasrabudhe, V. Rodriguez-Martinez, M. O’Meara, B. Farkas, Int. J. Food Prop. 20, 1965-1981 (2017)

18. A. L. Ahmad, M. M. H. S. Buddin, B. S. Ooi. Am. J. Chem. 5, 1-6 (2015) 